\title{
A Comparative Study on Hearing Aid Benefits of Digital Hearing Aid Use (BTE) from Six Months to Two Years
}

\author{
Lukeshwari Verma ${ }^{1}$ Himanshu Kumar Sanju ${ }^{2}$ Bibina Scaria ${ }^{1}$ Mayank Awasthi ${ }^{1} \quad$ Aparna Ravichandran ${ }^{1}$ \\ Ashritha Kaki ${ }^{1}$ Savalam Gnana Rathna Prakash ${ }^{1}$
} 1 Department of Audiology, Ali Yavar Jung National Institute of Hearing
Handicapped, Secunderabad, Andhra Pradesh, India
2Department of Audiology, AlISH, Manasagangothri, Mysore,
Karnataka, India
Address for correspondence Himanshu Kumar Sanju, Department of Audiology, AlISH, Manasagangothri, Mysore 570006, Karnataka, India (e-mail: himanshusanjuaiish@gmail.com).

Int Arch Otorhinolaryngol 2017;21:224-231.

\begin{abstract}
Introduction For many reasons, it is important for audiologists and consumers to document improvement and benefit from amplification device at various stages of uses of amplification device. Professional are also interested to see the impact of amplification device on the consumer's auditory performance at different stages i.e. immediately after fitting and over several months of use.

Objective The objective of the study was to measure the hearing aid benefit following 6 months - 1 -year usage, 1 year -1.5 yeaŕs usage, and 1.5 yeaŕs -2 years' usage.

Methods A total of 45 subjects participated in the study and were divided equally in three groups: hearing aid users from 6 months to 1 year, 1 year to 1.5 year, and 1.5 year to two years. All subjects responded to the Hearing Aid Benefit Questionnaire (63 questions), which assesses six domains of listening skills.

Result Results showed the mean scores obtained were higher for all domains in the

\section{Keywords}

- hearing aid

- acclimatization

- communication

- questionnaires

- elderly

- rehabilitation of hearing impairment aided condition, as compared with unaided condition for all groups. Results also showed a significant improvement in the overall score between first-time users with hearing aid experience of six months to one year and hearing aid users using hearing aids for a period between 1.5 and 2 years.

Conclusion It is possible to conclude that measuring the hearing aid benefit with the self-assessment questionnaires will assist the clinicians in making judgments about the areas in which a patient is experiencing more difficulty in everyday listening environment and in revising the possible technologies.
\end{abstract}

\section{Introduction}

It was estimated that hearing loss is most frequent disability, affecting more than 250 million people in the world. The impact of hearing disability is seen on emotional and behavioral wellbeing, social participation, quality of day to day life and employment status. ${ }^{1}$ According to 2001 census of India, the geriatric population in India was 57 million, which is very high in number

received

February 22, 2016

accepted

July 22, 2016

published online

September 2, 2016

10.1055/s-0036-1592117. ISSN 1809-9777. compared to 20 million in 1951. It was observed that there is a hike in geriatric population between 1991 to 2001 and it was estimated that by the year 2050 , the number of geriatric population would rise to 324 million. According, to Indian Council of Medical Research (ICMR), hearing loss is the most common morbidity followed by visual impairment. ${ }^{2}$

Humans are highly dependent on their senses. From these senses, they build their world and learn to conceptualize

Copyright $\odot 2017$ by Thieme Revinter

Publicações Ltda, Rio de Janeiro, Brazil

License terms 
things and to reason. Sensory organs play an important role in shaping both physical and psychological growth and behavior. All the senses contribute to provide meaningful experience to life, but hearing and vision - the distant senses - are the most crucial. The impact of hearing loss on any individuals and their families is extensive and it has an affect on day to day life. ${ }^{1}$ Any type of disability can lead to depression, whereas hearing loss can lead to number of losses. Hearing loss can results in interpersonal difficulties and career opportunities that may suffer from the notion that individuals skills are affected by the hearing loss. ${ }^{3,4}$

Age-related hearing loss not only attenuates sound, but also affects the clarity with which a spoken message is received. As older people face special problems of adjustment and uncertainty with advancing age, hearing loss can be of critical concern. Besides adding one more problem to the many already present for this group, a restricting hearing loss may cause the greatest difficulty in adjustment because of the limitation it places on communication. ${ }^{5}$ This view is upheld by the elderly persons themselves, who report hearing and vision first in importance for a healthy old age. Auditory deficiencies critically limit the person from participating in, and profiting from, the cultural and psychological warmth of verbal (language) and nonverbal (environmental) sounds.

Hearing loss disturb the individual ability to communicate effectively. Communication is important for improving and maintaining relationships and attribute of life, and hearing loss annihilate individual with hearing loss as well as their family and friends. As hearing loss may cause depression, isolation and withdrawal from life activities, it is very much important to include screen test for hearing loss in health assessment. ${ }^{6}$ For aural rehabilitation and management, amplification device plays a major role. The residual hearing is necessary for getting benefit from hearing aid. In current era, hearing aid includes digital component to improve signal quality and to fit different hearing loss. ${ }^{7}$

For many reasons, nowadays researchers are interested in the outcome measures of hearing aid. ${ }^{8-10}$ This passion of interest is because of several reasons, including professional lust to understand the effect of amplification device on listeners auditory performance at different stages of usages. Monitoring the hearing aid benefit in individuals can be accomplished both objectively and subjectively. Self-assessment questionnaires allow elders to rate their perception of hearing aid benefit in real world settings, that is, outside the confines of the soundproof booth, indicating not only whether they hear but also quantifying the benefit obtained from such devices in everyday listening environments.

Audiologic rehabilitation is considered efficacious when it reduces communication difficulties (i.e., auditory disabilities), enhances psychosocial well-being (i.e., handicap), and when the functional improvements remain long after the start of rehabilitation. Before proceeding, it is important to emphasize that, although hearing aids constitute the single most important part of the audiologic rehabilitation process, they constitute only one part and may not be indicated for certain hearing impaired individuals. ${ }^{11}$

\section{Need for the Study}

Outcome assessment is necessary in hearing aid fitting process. Professionals should must determine what "differences" should be measuring. It can be subjective or objective measures of hearing aid benefit.

Humes et al, in $1999^{12}$, reported that in earlier studies specific domain of hearing aid outcome were investigated, instead of broad range of outcome measures. Some researchers have investigated subjective measures, whereas others have focused on objective measures like speech recognition abilities, and some other have studies hearing aid satisfaction measures.

The habilitation \& rehabilitation approach used for individuals with hearing impairment ultimately aims for better quality of life. Data reveals that there is a tremendous increase in the purchase of hearing aids over the years, yet not much data are available on the outcomes of such devices. Whereas all the test materials developed for evaluating hearing impaired elders focus on diagnosis and intervention, the self-reported questionnaire focuses on the concept that the hearing aid benefit is important in understanding the communication and social participation of hearing impaired individuals in everyday life. Measuring the benefit will assist the clinicians in making judgments about the areas in which a patient is experiencing more difficulty in everyday listening environment and in revising the possible technologies. Highlighting the medical and socio-economic problems faced by the elderly people in India, helps bring forth strategies for improving their quality of life.

One of the most challenging issues confronting clinical researchers working in the area of hearing aids is the determination of those factors that result in a hearing-aid purchaser's becoming a successful user of amplification. Prevailing conventional clinical wisdom suggests that it is not uncommon to encounter patients with similar, if not identical, audiologic profiles regarding degree, configuration, and type of hearing loss, as well as etiology and age, yet demonstrating marked differences in their ability to use hearing aids successfully.

$\operatorname{Cox}^{13}$ studied subjective outcome of hearing aid fitting to find out the clientś point of view, which provides an overview of the measurement of hearing aid fitting outcomes in real life using self-reporting methods. It is important to note that selfreported data provide a unique view of the way that clients function and feel in their daily lives with regard to their hearing health.

In addition to assessing as many dimensions as possible, both objectively and subjectively, researchers working in this area must also decide when and how frequently to make such measurements. This has become more critical in light of the relatively recent findings regarding "acclimatization effects" in amplification. ${ }^{14}$ The outcome dimension focused on the study of acclimatization effects has primarily been that of hearing-aid benefit, measured both subjectively and objectively. ${ }^{15}$ Positive acclimatization effects have been observed in about half of the investigations studying this phenomenon, with a time course of $\sim 2-3$ months following the delivery of the hearing aids to the wearer. These studies, therefore, would suggest that hearing-aid benefit is not a very stable outcome 
dimension, especially over the first few months of hearing-aid use. It should be emphasized, however, that, to date, only about half of the studies of acclimatization have found a significant, positive acclimatization effect. ${ }^{15}$

Nonetheless, the existence of a significant acclimatization effect in several studies, with a focus on the dimension of hearing-aid benefit, raises the prospect that other hearing-aid outcome dimensions as well may be unstable over time. This raises a very fundamental issue for those attempting to quantify hearing-aid outcome in either research or clinical contexts, as to when and how frequently hearing-aid outcome should be measured.

Research related to Indian population is needed to build a much-needed database for pedagogical and clinical purposes to determine if the hearing aid was worn regularly and over a long period of time and to estimate the number of distinct dimensions of hearing-aid outcome. The intent was to increase understanding of differences in communication effectiveness and personal adjustment to hearing loss among individuals who represent the fastest growing segment of society with impaired hearing. This, in turn, is expected to yield information of importance for designing public education programs, focusing on prevention of hearing handicap, setting public health policy for hearing care among older adults, and developing clinical treatment programs targeted toward addressing the individual needs.

\section{Aim and Objective}

The aim of the present study was to obtain self-reporting hearing aid benefits and perceived benefit by family members from elderly digital BTE hearing aid wearers as a function of duration of usage. The objectives of the study were to measure the hearing aid benefit following 6 months to 1-year usage, 1 year to 1.5 yearś usage, and 1.5 year to 2 yearś usage.

\section{Method}

\section{Participants}

We recruited the participants in this study from two government institutes of speech and hearing using purposive sampling technique. A total of 45 subjects participated in the study and were divided into three groups each consisting of 15 subjects. Each participant met the following selection criteria: (a) age between 50 and 75 years; (b) hearing loss that was moderately severe to severe sloping (from 250 to $4000 \mathrm{~Hz}$, no inter-octave change in hearing thresholds of more than $20 \mathrm{~dB}$ ) in both ears from minimum of 2 years of age and maximum of 8 years of age; (c) hearing loss that was of sensorineural origin (normal tympanometry and air-bone gaps no greater than $10 \mathrm{~dB}$ at three or more frequencies); (d) hearing loss that was bilaterally symmetrical (interaural difference within $30 \mathrm{~dB}$ at all octave and half-octave intervals from 250 to $4000 \mathrm{~Hz}$ ); (e) living independently; (f) having no other pathologies; and $(\mathrm{g})$ able to complete printed questionnaires without assistance. All the subjects were using BTE digital hearing aid in both ears for a period of at least 6 months and up to 2 years. All hearing aids made use of linear circuits with output-limiting compression and Class D amplifiers.

\section{Tool}

We selected the Hearing Aid Benefit Questionnaire (English, Hindi \& Kannada version) developed by Kanwer as the test tool. ${ }^{16}$ The purpose of the scale is to measure communication effectiveness in a variety of situations and listening conditions. It consists of a total of 63 questions that evaluate hearing aid benefits in six domains, namely, communication in quiet, communication in noise, listening over telephone, listening to music, annoyance \& perceived benefit by the family members. It was translated along with instructions for patient and adapted into Telugu and Kannada (Native Language) whenever required as per the International Test Commission Guidelines for Translating and Adapting Tests. These questionnaires were translated in to Bengali and reverse translation was carried out make sure that the meaning of the content remains the same. These translated questions in Telugu were proofread by a native speaker of Telugu as well as having knowledge of English too. Later, same questionnaire was used for the participants under close supervision of audiologists.

\section{Procedure}

We collected data after obtaining written consent letters from each of the participants by explaining to them the aim, objective, and need for the study. We collected the demographic data of all the subjects using demographic data questionnaire. We used an interviewing method for collecting data from the client reporting to the center or nearby places. We administered the Hearing Aid Benefit Questionnaire translated and adapted from English into Telugu to the participants. The scale was administered to each participant individually as a paper-and-pencil task using a combined question-answer form. Instructions were to respond to each item on the basis of experience in one's usual listening mode, that is, with and without the use of hearing aids. The participants were requested to go through the instructions thoroughly and then rate it on a 5-point scale: (A) Never - 1 , (B) Occasionally - 2, (C) Half the time - 3, (D) Generally - 4, and (E) Always - 5. The Hearing Aid Benefit Questionnaire consists of 63 questions that evaluate hearing aid benefit in 6 domains, namely, communication in quiet, communication in noise, listening over telephone, listening to music, annoyance. Participants must rate the self-perceived scales to be rated while any one of the family members rate the perceived benefit. We calculated the responses obtained for each domain individually (higher score indicated greater perceived benefit) and computed total scores.

\section{Statistical Analysis}

We computed the mean and SD for all the domains individually. We used the independent ' $t$ ' test to find statistical significance between unaided (without hearing aid) and aided condition (with hearing aid) for overall score on five self-reporting domains for each group and also to find out significant differences for each individual domain.

We used repeated measures of ANOVA to compare the overall score obtained among the three groups and carried out post hoc analysis to compare between groups using SPSS software version 12 . 


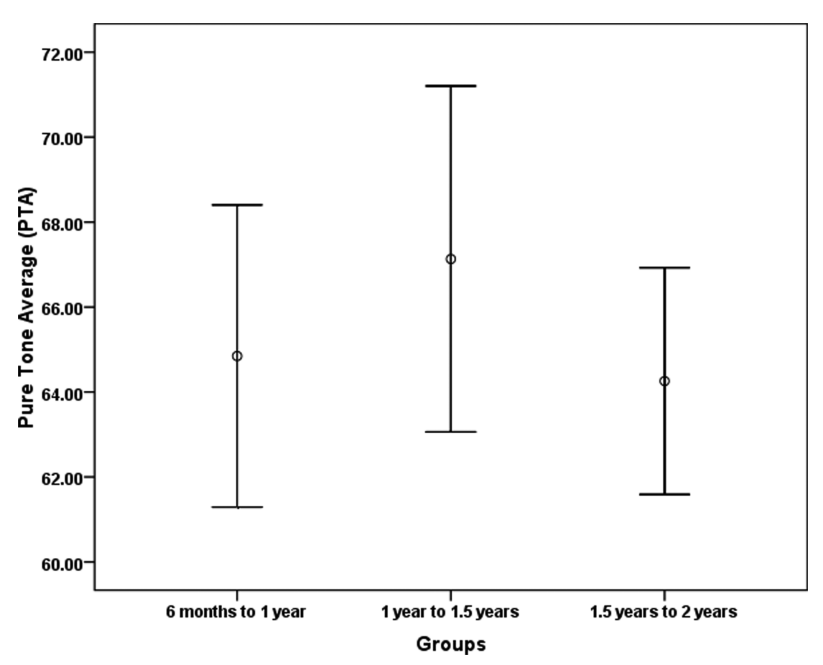

Fig. 1 Error bar graph of pure tone average across three groups.

\section{Results}

-Fig. 1 and -Fig. 2 show the error bar graph of pure tone average and word recognition scores for all three groups.

\section{From 6 Months to 1 Year}

To find out the significance between unaided and aided condition on the overall score of individuals using hearing aid for a period of six months to one year. The mean, standard deviation, $\mathrm{t}$-value, and significance is depicted in - Table 1. It is evident that the mean scores obtained were higher in aided condition as compared with unaided condition with the $t$ value significant $(t=24.60 ; p=0.00)$.

To find out the significant difference between unaided and aided condition on individual domains, we calculated the mean and SD values and applied the $t$-test. Results are indicated in - Table 2. It is evident that the mean values are significantly higher in aided condition than unaided condition level for all the domains.

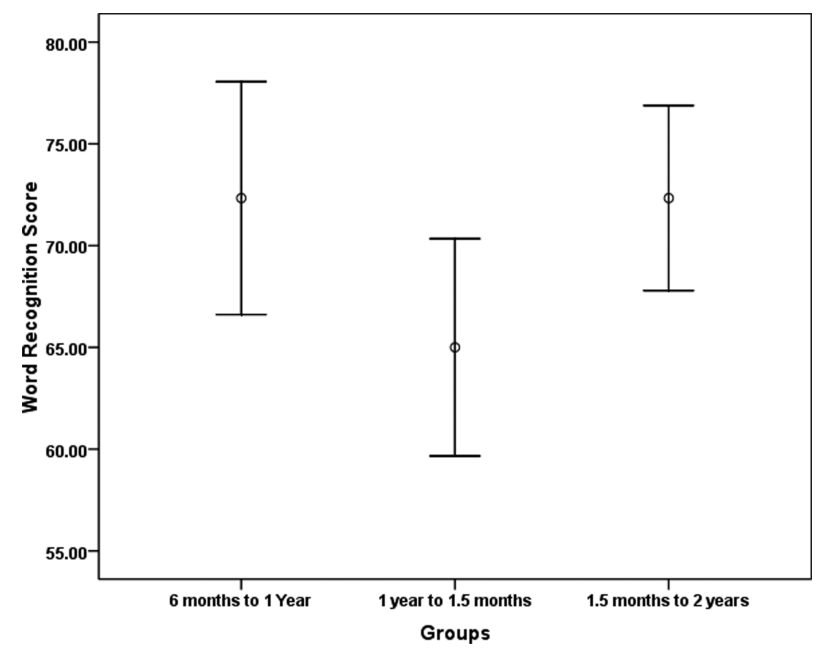

Fig. 2 Error bar graph of word recognition score across three groups.
Table 1 Mean, SD, $t$-value of overall scores for 6 months to 1 year of hearing aid usage

\begin{tabular}{|l|l|l|l|l|l|}
\hline Condition & $\mathrm{N}$ & Mean & SD & t-value & Significance \\
\hline $\begin{array}{l}\text { Without } \\
\text { hearing aid }\end{array}$ & 15 & 133.33 & 10.20 & 24.60 & 0.00 \\
\cline { 1 - 4 } $\begin{array}{l}\text { With } \\
\text { hearing aid }\end{array}$ & 15 & 198.66 & 6.65 & & \\
\hline
\end{tabular}

Abbreviations: SD, standard deviation.

To estimate the benefit derived from hearing aid on the perceived benefit by family member domain the scores of unaided and aided condition were compared using $t$-test and results indicate mean score to be higher in aided condition with $t$-value of 16.90 significant at $p<0.01$ level, as shown in - Table 3.

\section{From 1 Year to 1.5 Years}

The mean, standard deviation, $t$-value, and significance is depicted in - Table 4. It is evident that the mean scores obtained were higher in aided condition as compared with unaided condition with the $t$-value significant $(t=26.49$; $p=0.00$ ).

To find out the significant difference between unaided and aided condition on individual domains, we calculated the mean and SD values and applied the $t$-test. Results are indicated in - Table 5. It is evident from the table that the mean values are significantly higher in aided condition than unaided condition at $p<0.01$ level for all the domains.

To estimate the benefit derived from hearing aid on the perceived benefit by family member domain, we compared the scores of unaided and aided condition using $t$-test and results indicate the mean score to be higher in aided condition with $t$ value of 12.98 significant at $p<0.01$ level, as shown in -Table 6.

\section{From 1.5 to Two Years}

The mean, standard deviation, $\mathrm{t}$-value, and significance is depicted in - Table 7. It is evident that the mean scores obtained were higher in aided condition as compared with unaided condition with the $t$-value significant $(t=13.71$; $p<0.5$ ).

To find out the significant difference between unaided and aided condition on individual domains, we calculated the mean and SD values and applied the $t$-test. Results are indicated in - Table 8. It is evident from the table that the mean values are significantly higher in aided condition than unaided condition, significant at $p<0.01$ level for all the domains.

To estimate the benefit derived from hearing aid on the perceived benefit by family member domain, we compared the scores of unaided and aided condition using the $t$-test. Results indicate mean score to be higher in aided condition with $t$ value of 20.22, significant at $p=0.00$ level ( - Table 9). 
Table 2 Mean, SD, $t$-value and level of significance for each domain with hearing aid usage of 6 months to 1 year (Module 1-5 of selfrating scale)

\begin{tabular}{|c|c|c|c|c|c|c|}
\hline Domain & $\mathrm{N}$ & Condition & Mean & SD & $t$-value & Significance \\
\hline \multirow[t]{2}{*}{ Communication in quiet } & \multirow[t]{2}{*}{15} & Without h.a. & 45.93 & 5.77 & \multirow[t]{2}{*}{9.83} & \multirow[t]{2}{*}{0.00} \\
\hline & & With h.a. & 64.06 & 4.20 & & \\
\hline \multirow[t]{2}{*}{ Communication in noise } & \multirow[t]{2}{*}{15} & Without h.a. & 36.00 & 5.23 & \multirow[t]{2}{*}{10.42} & \multirow[t]{2}{*}{0.00} \\
\hline & & With h.a. & 53.47 & 3.83 & & \\
\hline \multirow[t]{2}{*}{ Listening over telephone } & \multirow[t]{2}{*}{15} & Without h.a. & 27.00 & 5.05 & \multirow[t]{2}{*}{9.50} & \multirow[t]{2}{*}{0.00} \\
\hline & & With h.a. & 41.20 & 2.80 & & \\
\hline \multirow[t]{2}{*}{ Listening to music } & \multirow[t]{2}{*}{15} & Without h.a. & 11.13 & 1.92 & \multirow[t]{2}{*}{9.25} & \multirow[t]{2}{*}{0.00} \\
\hline & & With h.a. & 16.60 & 1.24 & & \\
\hline \multirow[t]{2}{*}{ Annoyance } & \multirow[t]{2}{*}{15} & Without h.a. & 15.00 & 2.80 & \multirow[t]{2}{*}{8.84} & \multirow[t]{2}{*}{0.00} \\
\hline & & With h.a. & 23.13 & 2.19 & & \\
\hline
\end{tabular}

Abbreviations: h.a., hearing aid; SD, standard deviation.

Table 3 Mean, SD, $t$-value, and significance on the perceived benefit by family member domain with hearing aid usage for 6 months to 1 year of usage (Module $1-5$ of self-rating scale)

\begin{tabular}{|l|l|l|l|l|l|}
\hline Condition & $\mathrm{N}$ & Mean & SD & $t$-value & Significance \\
\hline $\begin{array}{l}\text { Without } \\
\text { hearing aid }\end{array}$ & 15 & 29.27 & 3.32 & 16.90 & 0.00 \\
\cline { 1 - 4 } $\begin{array}{l}\text { With } \\
\text { hearing aid }\end{array}$ & 15 & 48.53 & 2.90 & & \\
\hline
\end{tabular}

Abbreviations: SD, standard deviation.
Table 4 Mean, SD, $t$-value, and significance of overall scores for 1 year to 1.5 years of hearing aid usage

\begin{tabular}{|l|l|l|l|l|l|}
\hline Condition & $\mathrm{N}$ & Mean & SD & t-value & Significance \\
\hline $\begin{array}{l}\text { Without } \\
\text { hearing aid }\end{array}$ & 15 & 148.73 & 5.42 & 26.49 & 0.00 \\
\cline { 1 - 4 } $\begin{array}{l}\text { With } \\
\text { hearing aid }\end{array}$ & 15 & 202.20 & 5.63 & & \\
\hline
\end{tabular}

Abbreviations: SD, standard deviation.

Table 5 Mean, SD, $t$-value, and level of significance for each domain with hearing aid usage of 1 year -1.5 years (Module 1-5of selfrating scale)

\begin{tabular}{|c|c|c|c|c|c|c|}
\hline Domain & $\mathrm{N}$ & Condition & Mean & SD & $t$-value & Significance \\
\hline \multirow[t]{2}{*}{ Communication in quiet } & \multirow[t]{2}{*}{15} & Without h.a. & 50.40 & 3.48 & \multirow[t]{2}{*}{12.83} & \multirow[t]{2}{*}{0.00} \\
\hline & & With h.a. & 65.47 & 2.92 & & \\
\hline \multirow[t]{2}{*}{ Communication in noise } & \multirow[t]{2}{*}{15} & Without h.a. & 38.20 & 4.47 & \multirow[t]{2}{*}{10.65} & \multirow[t]{2}{*}{0.00} \\
\hline & & With h.a. & 53.87 & 3.52 & & \\
\hline \multirow[t]{2}{*}{ Listening over telephone } & \multirow[t]{2}{*}{15} & Without h.a. & 32.53 & 4.08 & \multirow[t]{2}{*}{5.86} & \multirow[t]{2}{*}{0.00} \\
\hline & & With h.a. & 40.60 & 3.41 & & \\
\hline \multirow[t]{2}{*}{ Listening to music } & \multirow[t]{2}{*}{15} & Without h.a. & 11.73 & 1.33 & \multirow[t]{2}{*}{13.67} & \multirow[t]{2}{*}{0.00} \\
\hline & & With h.a. & 17.80 & 1.08 & & \\
\hline \multirow[t]{2}{*}{ Annoyance } & \multirow[t]{2}{*}{15} & Without h.a. & 15.87 & 2.87 & \multirow[t]{2}{*}{9.05} & \multirow[t]{2}{*}{0.00} \\
\hline & & With h.a. & 23.73 & 1.75 & & \\
\hline
\end{tabular}

Abbreviations: h.a., hearing aid; SD, standard deviation. 
Table 6 Mean, SD, $t$-value, and significance on the perceived benefit by family member domain with hearing aid usage of 1 year to 1.5 years (Module $1-5$ of self-rating scale)

\begin{tabular}{|l|l|l|l|l|l|}
\hline Condition & $\mathrm{N}$ & Mean & SD & t-value & Significance \\
\hline $\begin{array}{l}\text { Without } \\
\text { hearing aid }\end{array}$ & 15 & 36.67 & 2.43 & 12.98 & 0.00 \\
\cline { 1 - 4 } $\begin{array}{l}\text { With } \\
\text { hearing aid }\end{array}$ & 15 & 50.27 & 3.24 & & \\
\hline
\end{tabular}

Abbreviations: SD, standard deviation.

\section{Among Three Groups}

We used one-way ANOVA to compare the test score among the three groups in terms of between-group and withingroup variables. Results were obtained in form of F-ratio. The F-ratio is 4.546 , which is greater than the f probability, indicating that there is significant difference across 3 groups. Thus, the performance of adults in the three groups (individuals with hearing aid usage of 6 months to 1 year, individuals with hearing aids usage of 1 year to 1.5 years, and individuals with hearing aids usage of 1.5 years to 2 years) is statistically significant (-Table 10).

Post hoc analysis between groups shows the mean difference between groups $1 \& 3$ is higher than between groups $1 \& 2$ and $2 \& 3$, indicating that there is a significant effect of hearing-aid experience (-Table 11).

\section{Discussion}

The results of the present study showed an improvement in self-reported outcome over time in hearing-aid users. There was a significant difference in the improvement between first-time users with hearing aid experience of 6 months to 1 year and hearing aid users using hearing aid between 1.5 to 2 years on the overall score of five self-reporting domains of HAQ. According to Arlinger in 1996, auditory acclimatization
Table 7 Mean, SD, $t$ value of overall scores of 1.5 year to 2 years of hearing aid usage

\begin{tabular}{|l|l|l|l|l|l|}
\hline Condition & $\mathrm{N}$ & Mean & SD & t-value & Significance \\
\hline $\begin{array}{l}\text { Without } \\
\text { hearing aid }\end{array}$ & 15 & 151.53 & 5.75 & 13.71 & 0.235 \\
\cline { 1 - 4 } $\begin{array}{l}\text { With } \\
\text { hearing aid }\end{array}$ & 15 & 209.66 & 15.37 & & \\
\hline
\end{tabular}

Abbreviations: SD, standard deviation.

refers to improvement in auditory performance with amplification device with time. ${ }^{17}$ It is well reflected in outcome of present study i.e. improvement in auditory performance with time.

The present study also showed that the auditory performance was getting better over time. This type of finding shows that individual with hearing aid require listening experience in various situations before evaluation. The results of our study correlated with Brooks and Bulmer ${ }^{18}$ who reported on improvements in the quality of life and in the individuals' social life with the use of the hearing aid.

The domains represent the self-assessed hearing-aid benefit perceived by the participants with and without hearing aid for the conditions: communication in quiet, communication in noise, listening over telephone, listening to music, and annoyance. In general, across all domains, hearing aids were judged to be "helpful." However, the perceived benefit provided by hearing aids varied significantly across the domains, as confirmed with a repeated-measures analysis of variance. Thus, the hearing aids were most helpful in quiet listening conditions, significantly less helpful for non-speech stimuli like music. Similar results have been obtained previously by Walden et al. ${ }^{19}$ Malinoff and Weinstein ${ }^{20}$ showed a significant reduction in handicap following three weeks of hearing aid use.

Table 8 Mean, SD, 't'- value and level of significance for each domain with hearing aid usage of 1.5 year to 2 years (Module 1-5 of self-rating scale)

\begin{tabular}{|c|c|c|c|c|c|c|}
\hline Domain & $\mathrm{N}$ & Condition & Mean & SD & $t$-value & Significance \\
\hline \multirow[t]{2}{*}{ Communication in quiet } & \multirow[t]{2}{*}{15} & Without h.a. & 52.60 & 3.64 & \multirow[t]{2}{*}{8.02} & \multirow[t]{2}{*}{0.00} \\
\hline & & With h.a. & 64.13 & 4.20 & & \\
\hline \multirow[t]{2}{*}{ Communication in noise } & \multirow[t]{2}{*}{15} & Without h.a. & 36.80 & 4.33 & \multirow[t]{2}{*}{14.47} & \multirow[t]{2}{*}{0.00} \\
\hline & & With h.a. & 57.06 & 3.28 & & \\
\hline \multirow[t]{2}{*}{ Listening over telephone } & \multirow[t]{2}{*}{15} & Without h.a. & 33.07 & 3.94 & \multirow[t]{2}{*}{8.10} & \multirow[t]{2}{*}{0.00} \\
\hline & & With h.a. & 42.73 & 2.43 & & \\
\hline \multirow[t]{2}{*}{ Listening to music } & \multirow[t]{2}{*}{15} & Without h.a. & 11.73 & 1.22 & \multirow[t]{2}{*}{13.78} & \multirow[t]{2}{*}{0.00} \\
\hline & & With h.a. & 17.27 & 0.96 & & \\
\hline \multirow[t]{2}{*}{ Annoyance } & \multirow[t]{2}{*}{15} & Without h.a. & 16.87 & 1.80 & \multirow[t]{2}{*}{12.14} & \multirow[t]{2}{*}{0.00} \\
\hline & & With h.a. & 24.93 & 1.83 & & \\
\hline
\end{tabular}

Abbreviations: h.a., hearing aid; SD, standard deviation. 
Table 9 Mean, SD, $t$ value and significance on the perceived benefit by family member domain with hearing aid usage of 1.5 - 2 years (Module $1-5$ of self-rating scale)

\begin{tabular}{|l|l|l|l|l|l|}
\hline Condition & $\mathrm{N}$ & Mean & SD & $t$-value & Significance \\
\hline $\begin{array}{l}\text { Without } \\
\text { hearing aid }\end{array}$ & 15 & 32.93 & 2.86 & 20.22 & 0.00 \\
\cline { 1 - 4 } $\begin{array}{l}\text { With } \\
\text { hearing aid }\end{array}$ & 15 & 52.27 & 2.34 & & \\
\hline
\end{tabular}

Table 11 Mean \& significance of comparisons between each group

\begin{tabular}{|l|l|l|l|}
\hline Condition & $\begin{array}{l}\text { Between } \\
\text { groups }\end{array}$ & $\begin{array}{l}\text { Mean } \\
\text { difference }\end{array}$ & Significance \\
\hline \multirow{2}{*}{$\begin{array}{l}\text { With } \\
\text { hearing aid }\end{array}$} & $1 \& 2$ & 3.53 & 0.348 \\
\cline { 2 - 4 } & $1 \& 3$ & 11.00 & 0.005 \\
\cline { 2 - 4 } & $2 \& 3$ & 7.47 & 0.052 \\
\hline
\end{tabular}

Cox and Alexanader in $1992^{21}$ reported significant benefit over time among hearing aid users. They also observed that the improvement was small in noisy situation and adverse listening conditions. Turner et al, in $1996^{15}$, investigated that many studies found similar and overlapping results.

Wong et al, in $2004^{22}$, found a relation between expectation and perceived benefit. They reported that perceived benefit did not always leads to satisfaction, greater satisfaction can be achieved with fulfillment of desired expectation. The scale also predicts the outcomes on the domain of perceived benefit by family member which also shows that the perceived benefit provided by the hearing aid is better than the unaided condition for all the three groups. Moreover, there is improvement in the mean scores across the duration of usage, indicating that acclimatization effects are also clearly perceived by the family members.

The hearing aid benefit questionnaire possesses several features, which make it potentially useful for a variety of applications. First, all items in the scale were directed specifically toward everyday hearing experiences. Because of the logical relevance of items to common hearing experiences, the instrument is accepted by hearing-impaired persons as a reasonable means of inquiring into their hearing difficulties. Second, the language of the items was kept at a low level of difficulty so that the scale would be appropriate for a wide age span and for a broad range of language abilities. Third, the internal consistency reliability of the scale is sufficiently high to permit accurate determination of handicap for individual subjects.

The self-appraisal scale has potential usefulness in the clinic to predict acclimatization effects and hearing aid benefit. For a small investment of patient testing time - about five minutes - it is possible to obtain a systematic view of the patient's assessment of specific hearing activities in quantitative form. It will also indicate the significant improvement in the quality of life in individuals with hearing impairment. However, the limitation of the present study is that three
Table 10 The mean \& standard deviation of test scores for all the groups

\begin{tabular}{|l|l|c|c|l|l|}
\hline Group & Condition & Mean & SD & F-value & Significance \\
\hline $\begin{array}{l}\text { With } \\
\text { hearing } \\
\text { aid }\end{array}$ & $\begin{array}{l}6 \text { months } \\
-1 \text { year }\end{array}$ & 198.67 & 6.65 & 4.546 & 0.016 \\
\cline { 2 - 4 } & $1-1.5$ year & 202.20 & 5.63 & & \\
\cline { 2 - 4 } & $1.5-2$ years & 209.67 & 15.37 & & \\
\hline
\end{tabular}

Abbreviations: SD, standard deviation.

groups of participants were taken into consideration. It would be more powerful, albeit time consuming, to examine one group over time. Then one could truly determine whether the benefit of hearing aids persists over time. Longitudinal study in this area can bring more powerful outcomes.

\section{Conclusion}

Our study allows us to conclude that measuring the hearing aid benefit with the self-assessment questionnaires will assist the clinicians in making judgments about the areas in which a patient is experiencing more difficulty in everyday listening environment and in revising the possible technologies. It also highlights the medical and socio-economic problems faced by the elderly and helps in bringing up strategies for improving their quality of life. The scale can also be used in comparing multiple hearing aid fittings, and tracking success with hearing aids over time.

\section{Reference}

1 Northern JL, Downs MP. Hearing in children. Lippincott Williams \& Wilkins; 2002

2 Shah B, Prabhakar AK. Chronic morbidity profile among elderly. Indian J Med Res 1997;106:265-272

3 Mulrow CD, Tuley MR, Aguilar C. Correlates of successful hearing aid use in older adults. Ear Hear 1992;13(2):108-113

4 Yueh B, Shapiro N, MacLean CH, Shekelle PG. Screening and management of adult hearing loss in primary care: scientific review. JAMA 2003;289(15):1976-1985

5 Dalton DS, Cruickshanks KJ, Klein BE, Klein R, Wiley TL, Nondahl DM. The impact of hearing loss on quality of life in older adults. Gerontologist 2003;43(5):661-668

6 Grewal I, Lewis J, Flynn T, Brown J, Bond J, Coast J. Developing attributes for a generic quality of life measure for older people: preferences or capabilities? Soc Sci Med 2006;62(8):1891-1901

7 Alpiner JG, McCarthy PA, Eds. Rehabilitative audiology: Children and Adults. Lippincott Williams \& Wilkins; 2000

8 Bentler RA, Niebuhr DP, Getta JP, Anderson CV. Longitudinal study of hearing aid effectiveness. I: Objective measures. J Speech Hear Res 1993;36(4):808-819

9 Dillon H, James A, Ginis J. Client Oriented Scale of Improvement (COSI) and its relationship to several other measures of benefit and satisfaction provided by hearing aids. J Am Acad Audiol 1997;8(1):27-43

10 Mulrow CD, Tuley MR, Aguilar C. Sustained benefits of hearing aids. J Speech Hear Res 1992;35(6):1402-1405

11 Stephens D. Hearing rehabilitation in a psychosocial framework. Scand Audiol Suppl 1996;43:57-66

12 Humes LE. Dimensions of hearing aid outcome. J Am Acad Audiol 1999;10(1):26-39 
13 Cox RM. Assessment of subjective outcome of hearing aid fitting: getting the client's point of view. Int J Audiol 2003;42(Suppl 1):S90-S96

14 Gatehouse S. The time course and magnitude of perceptual acclimatization to frequency responses: evidence from monaural fitting of hearing aids. J Acoust Soc Am 1992;92(3):1258-1268

15 Turner CW, Humes LE, Bentler RA, Cox RM. A review of past research on changes in hearing aid benefit over time. Ear Hear 1996;17(3, Suppl)14S-25S

16 Navdeep Kanwer. Development of hearing aid benefit questionnaire for adults. Unpublished master's dissertation. June 2011

17 Arlinger S, Gatehouse S, Bentler RA, et al. Report of the Eriksholm Workshop on auditory deprivation and acclimatization. Ear Hear 1996;17(3, Suppl)87S-98S
18 Brooks DN, Bulmer D. Survey of binaural hearing aid users. Ear Hear 1981;2(5):220-224

19 Walden BE, Schwartz DM, Williams DL, Holum-Hardegen LL, Crowley JM. Test of the assumptions underlying comparative hearing aid evaluations. J Speech Hear Disord 1983;48(3): 264-273

20 Malinoff RL, Weinstein BE. Measurement of hearing aid benefit in the elderly. Ear Hear 1989;10(6):354-356

21 Cox RM, Alexander GC. Maturation of hearing aid benefit: objective and subjective measurements. Ear Hear 1992;13(3):131-141

22 Wong LL, Hickson L, McPherson B. Hearing aid satisfaction: what does research from the past 20 years say? Trends Amplif 2003; 7(4):117-161 